\title{
Geleentheidsrede
}

\section{Die soeke na sin en rede \\ Enkele romans van Eco en Mulisch ${ }^{1}$}

\author{
Willem J. Ouweneel \\ Huis ter Heide \\ NEDERLAND \\ E-pos: wj ouweneel@wxs.nl
}

Dit is met die grootste voldoening dat ek aan die nege winters terugdink waarin ek my kragte aan hierdie Universiteit gewy het. 'n Mens wonder: waaroor het ek al dié tyd gepraat? Wat was die boodskap wat ek aan dosente en studente wou bring? Miskien kan ek dit in één sin saamvat: dit het gegaan oor die vraag wat Christelike wetenskap is. Vandag gaan ek egter nie probeer om my antwoord op hierdie vraag nog 'n keer op die gebruiklike manier onder woorde te bring nie. Nee, ek wil probeer om iets oor hierdie vraag te sê deur middel van 'n metode wat ek in dié nege jare nog nooit gebruik het nie, naamlik dié van die literatuurwetenskap. Ek wil met ander woorde op enkele besondere literêre romans wys, twee romans van 'n Italianer en een van 'n Nederlander: Umberto Eco en Harry Mulisch.

\section{Die taalwetenskaplike Umberto Eco}

Eco het by Jan publiek veral bekend geword op grond van drie romans: Il nome della rosa ("Die naam van die roos", 1980), Il pendolo di Foucault ("Die slinger van Foucault", 1988) en L'Isola del giorno prima ("Die eiland van die vorige dag", 1994) ${ }^{2}$ In hierdie wêreldberoemde romans word die leser spelenderwys ingewy in die geskiedenis van die Westerse denke. In die eerste roman is dit die denke van die Middeleeue, in die tweede boek ook die denke van die Oudheid 
en van die teenswoordige tyd, en in die derde roman die denke van die opkomende natuurwetenskap in die $17 \mathrm{de}$ eeu.

\section{Wetenskap is 'n orde-ontsluitende aktiwiteit}

Wat het hierdie romans met die vraag omtrent Christelike wetenskap te doen? Een van die dinge wat ek by hierdie universiteit baie beklemtoon het, is dat wetenskap 'n orde-ontsluitende aktiwiteit is. Omdat daar 'n Wetgewer, 'n Goddelike Wetgewer is, is daar in die geskape werklikheid ook 'n wetsorde, 'n wetmatige orde waaraan alle geskape dinge onderwerp is. Wetenskap kan omskryf word as die poging om hierdie wetsorde op te spoor. Die groot vraag is egter: hoe is ons verseker dat so 'n orde regtig bestaan? Dit is opvallend hoe seker die meeste natuurwetenskaplikes is dat die orde bestaan, terwyl talle filosowe eerder vermoed dat die mens 'n orde ontwerp, uitdink. Party postmoderniste noem hierdie ontworpe ordes "groot verhale" of meesterverhale. Voorbeelde van sulke meesterverhale is die Christendom, die Marxisme, die Freudianisme, die Darwinisme. Almal het geprobeer om die hele werklikheid in één magtige ontwerp saam te vat en hierdie ontwerp as die uiteindelike waarheid aan te bied.

\section{Die tyd van meesterverhale is verby}

Die postmodernisme glo egter dat die tyd van al hierdie "meesterverhale" verby is. Eco se roman, Die naam van die roos, is die uitbeelding van hierdie idee dat daar geen universele orde meer is wat die hele wêreld kan verklaar nie. In dié roman vind ons die volgende veelseggende woorde van een van die hoofpersone, naamlik die geleerde William van Baskerville, wat in 'n Middeleeuse klooster 'n hele reeks moorde oplos deurdat hy glo dat die moorde die orde van die Bybelboek Openbaring weerspieël Aan die einde van die boek sê hy egter (Eco, 1983:512 e.v)

'( ... ) Ek het my soos 'n styfkop gedra deur agter 'n skyn van orde aan te jaag, terwyl ek baie goed moes geweet het dat daar in die heelal geen orde is nie.'

[Dan antwoord sy leerling Adson.]

'Maar deur ' $n$ verkeerde orde te bedink, het $u$ tog iets gevind ...'

[En William antwoord]

'Jy het iets baie moois gesê, Adson, baie dankie. Die orde wat ons gees bedink, is soos 'n net, of 'n leer, wat 'n mens konstrueer om êrens uit te kom. Maar daamá moet 'n mens daardie leer weggooi omdat 'n mens ontdek dat die leer, ofskoon dit goeie dienste gelewer het, sy sin verloor het. ( ... ) die enigste waarhede wat bruikbaar is, is werktuie wat 'n mens ná gebruik weggooi.' (Vertaling: HWJO.)

Bogenoemde siening is 'n tipies postmoderne opvatting van wetenskap - 'n opvatting wat nou al enkele dekades lank verkondig word. Dit impliseer dat daar 
geen kosmiese orde is wat ontdek kan word nie, maar dat wetenskaplikes aan die kosmos slegs 'n orde toeskryf, om die kosmos daardeur te leer beheers. Die meeste fisici en bioloë sou daarmee glad nie saamstem nie; hulle glo nog altyd dat hulle besig is om 'n bestaande orde op te spoor. Talle filosowe glo egter dat 'n orde slegs ontwerp en aan die wêreld toegeken word. Waarheid is nie langer dit wat op die wetsorde teruggaan, en daarmee op die Goddelike Wetgewer dui nie. Nee, waarheid is slegs dit wat werk. En as dit gewerk het, het jy dit nie meer nodig nie en kan jy dit maar weggooi. Die orde wat op hierdie manier beskryf word, kan ons help om ons pad in die werklikheid te vind. Dit beteken egter nie dat daardie orde as sodanig op enige objektiewe waarheid berus, of dat dit moontlik is om die bestaan van so 'n orde aan te toon nie - om nie eers daarvan te praat om so 'n orde te vind nie. Die mens ontdek geen orde nie, maar bedink dit. As dit nuttige resultate oplewer, verander dit niks aan die feit dat dit om 'n orde gaan wat bedink is nie (vgl. Ouweneel, 1997:112-115).

In werklikheid is dit ook presies die tema van Umberto Eco se tweede roman, Die slinger van Foucault. Die oorspronklike slinger, waarmee Foucault die aardrotasie aangetoon het, hang steeds in 'n museum in Parys. Eco se boek begin en eindig met ' $n$ verwysing na hierdie slinger. Die slinger is 'n simbool vir ' $n$ vaste punt in die heelal, waarna die drie hoofpersone van die boek op soek is. Hulle bedink (bedink!) 'n plan, wat in die boek tot dramatiese ontwikkelings lei. ${ }^{3}$ In hierdie sielkundige werk word die geskiedenis beskou as 'n komplot, 'n sameswering van misterieuse kragte, waarin alles uit die verlede en hede inderdaad met mekaar saamhang. Daarby maak dit nie saak van watter klassieke simbole die roman gebruik maak nie: die heilige graal, die alchemistiese steen van die wyses, die goue vlies van die Argonaute, die geheim van die groot Egiptiese piramide, die verborge skat van die Middeleeuse orde van die Tempeliers, of gewoon: "die plan", "die geheim". Dit gaan om die "groot geheim" van die kosmos. Wat is die wesenlike van die kosmos en van die lewe? Die geskiedenis van die Westerse denke bly die soektog na die wesenlike, na die geheim van die lewe. Die groot vraag is egter: bestaan daar so "n "groot geheim" en kan ons dit leer ken?

In die postmoderne kultuur is dit heeltemal geoorloof om te ontken dat die wesenlike bestaan. Waarheid is mos dit wat werk, wat vir jou nuttig is. As jy in die "groot geheim" wil glo, soos Christene dit wil doen, en dit gee vir jou bevrediging, dan werk dit vir jou; dan is dit jou "waarheid". Maar as die

In die derde roman, Die eiland van die vorige dag, skuif allerlei bedinkte verhalen in mekaar Die skrywer bedink 'n ek-figuur in dic boek, wat op grond van aantekeninge wat gevind is ' $n$ storic oor Roberto bedink, terwyl 'n groot deel van hierdie storie in beslag geneem word deur stories wat Roberto self weer bedink omtrent sy denkbeeldige broer Ferrante. So lyk ook die postmodeme menselewe - 'n vervlegting van talle "stories". wat nie langer 'n "afbeelding" van enige "objektiewe werklikheid" vorm nie - vir sover dit al bestaan 
ontkenning van enige Geheim jou voldoende eksistensiële bevrediging gee, dan is hierdie ontkenning jou "waarheid". Dan word die wesenlike van die lewe eenvoudig dat daar geen essensies bestaan nie. Myns insiens is dit juis die boeiende van Eco se tweede roman: die "groot geheim" word deur die drie hoofpersone ontwerp, bedink as 'n wilde spel van die fantasie. Maar as die bedinkte Geheim onthul word, blyk dit dat talle persone op soek is na dieselfde Geheim. Is die blote feit dat hulle almal daarna soek 'n bewys dat die "groot geheim"werklik "waar" is? Of mag ons sê dát die "geheim" reeds "waar" is bloot omdat dit so baie geskiedkundige feite in 'n "sinvolle" verband plaas? Is Christendom, Marxisme of Darwinisme reeds "waar" as daar maar voldoende mense is wat hierdie "waarhede" as "sinvol" ervaar? Is die hele mensheid dalk net op soek na 'n laaste, vaste grond, waarin die menslike hart rus kan vind? Augustinus het gesê: "onrustig is ons hart, totdat dit rus vind in $U$ ". Hierdie " $U$ " mag vandag op werklik alle moontlike maniere ingevul word; maar 'ons hart' bly altyd om so 'n invulling vra. En as jy die rus gevind het, maak dit nie saak watter ding dit is waarin jy jou rus gevind het nie; dan is dit vir jou die laaste waarheid, die oplossing van die groot Lewensgeheim

Eco se roman is 'n rustelose soektog na die "gode" wat aan ons lewe sin en inhoud kan gee, sonder dat dit ooit werklik duidelik word of hierdie gode wel "objektief bestaan". Inteendeel, die ek-figuur in die boek vra vir homself of 'n geheim wat verklaar word, nog wel waarheid kan wees. Hierdie siening is ook weer tipies postmodernisties. 'n Geheim wat opgelos word, kan geen waarheid wees nie - of dit nou godsdienstige, filosofiese of vakwetenskaplike waarheid is, 'n waarheid wat op alle vrae 'n antwoord het, is geen waarheid nie. Die ware geheim omtrent die werklikheid is per definisie onbereikbaar. Die boek se hoofpersoon vra op die ou end met betrekking tot die "groot geheim" (Eco, 1989:632 e.v. - vertaald).

... Bestaan daar so 'n wonderlike geheim?

Seker, op voorwaarde dat jy dit nooit te wete kom nie. In ontslujerde vorm kan die Geheim ons maar net teleurstel. (...) [En dan noem hy 'n voorbeeld] Tog het daar nog maar net iemand gekom wat verklaar het dat Hy die Seun van God is, die vleesgeworde Seun van God wat van die wêreldse sondes verlos. Was dit dalk ' $n$ betekenislose misterie? Hy het almal die verlossing belowe, as jy maar net jou naaste liefhet. Was dit dalk ' $n$ waardelose geheim [d.i. net omdat dit hier om 'n waarheid gaan wat op alle vrae 'n antwoord het]? (...) [Of gaan dit in in werklikheid dalk om] ' $n$ ander wete, wat verlore gegaan het, waarvan die [gangbare Christelike] dogmas maar net die buitekant was? (...) Daar was iemand, miskien Rubinstein, wat, toe hulle hom vra of hy in God glo, geantwoord het: 'O nee, ek glo ... in iets wat baie groter is ...' Maar ' $n$ ander persoon (dalk Chesterton?) het gesê: sedert mense nie meer in God glo nie, glo hulle nie in niks nie, maar glo hulle in alles. 
Alles is nie 'n groter geheim nie. Daar is geen groter geheime nie, want sodra hulle onthul word, lyk hulle klein. Daar is slegs 'n leë geheim. 'n Geheim wat weggly ...

In die boek se ontknoping is daar inderdaad sprake van 'n "leë" geheim, iets wat egter 'n geheim moet bly, omdat 'n onthulde geheim die grootste ontgogeling is. So het die Christendom vir die meeste teenswoordige mense 'n ontgogeling geword, maar so ook die Marxisme, die Freudianisme, die Darwinisme. Op hierdie wyse bly die hele mensheid gevang in 'n "groot geheim": die groot vraag na die aard van die werklikheid en die sin van die lewe. Hierdie geheim is en bly 'n diep misterie, maar is tegelyk "leeg" (vgl. Eco, 1989:634 e.v). Geen enkele groot meesterverhaal geld en is tersaaklik nie. Vir die teenswoordige mens is die Christelike geheim nie langer aanvaarbaar nie, maar ook alle ander geheime wat hulle plek ingeneem het, is op dieselfde manier ontmasker: hulle is sowel leeg as oneg. Wat oorbly, is slawerny en die onderwerping aan die Groot Meester, soos Eco dit noem. Dit is die Meester, die Satan, aan wie die teenswoordige mens homself willoos sal uitlewer.

In sekere opsigte herinner boeke soos Eco s'n aan die indrukwekkendste roman van die Nederlandse skrywer Harry Mulisch, naamlik Die ontdekking van die hemel (1992). Mulisch het hierdie roman onlangs aan die pous in Rome oorhandig. Eco se roman verteenwoordig die soektog na die geheim, Mulisch se roman impliseer die soektog na die hemel. Ten diepste gaan dit egter steeds om dieselfde saak, of selfs om dieselfde persoon - dit wat sommige mense God noem. Hierdie romans vra implisiet of daar ook in ons tyd en vir die toekoms nog 'n 'iets' of 'n 'iemand' oorbly, wat dit die moeite werd maak dat mense daarna bly soek. Hoe progressief 'n mens ook al mag wees, hy bly vra en soek na die "groot geheim". Hy kán nie anders nie, daarvoor is hy mens. Die resultaat van hierdie soektog is egter in die post-Christelike en postmoderne tydperk beslis nie meer seker nie. In Eco se roman is die geheim selfs "leeg". Mulisch se roman suggereer dat die weg tot God nie meer bestaan nie, deurdat God self hierdie pad afgesny het.

Ek ken geen roman wat méér raakvlakke met die moderne wetenskap vertoon, as Die ontdekking van die hemel (Mulisch, 1992) nie - of dit nou om die fisika, die kunsgeskiedenis, die literatuurwetenskap, die teologie, die musikologie of die wysbegeerte gaan. Dit is geen wonder dat geen Nederlandse roman méér bespreek is as hierdie boek nie - nie net in talle koerant- en tydskrifartikels nie maar ook in hele studies in boekvorm. (Die vernaamste besprekings is Steenhuis, 1995, De Rover, 1995 en Haan et al., 1995.) Die roman gee treffend weer hoe talle mense vandag die verhouding tussen God en die mensheid belewe: nie die mens het die band met God verloor nie, maar God het hierdie band van sy kant verbreek. Die hele verhaal van meer as negehonderd bladsye loop uit op hierdie verskriklike gegewe: God vat letterlik die twee kliptafels van die aarde weg. Hy is nie meer die "Wetgewer" nie, maar, soos die titel van die 
tersaaklike hoofstuk lui: die "Wetnemer" Die Tien Gebooie is die voorwaardes van die verbond wat God met Israel, maar eintlik met die hele mensheid gesluit het. As die mens hierdie voorwaardes radikaal verbreek, hef God ook sy verbond met die mensheid op en wel deur die Tien Gebooie terug te vat. Op die vraag hoekom God sy hande van die wêreld afgetrek het, antwoord Mulisch regstreeks: die belangrikste oorsaak daarvan is die moderne wetenskap, wat homself tussen God en die wêreld geplaas het.

Reeds in die titel van Mulisch se verhaal lê 'n sekere dubbelsinnigheid. Die uitdrukking "van die hemel" kan wys op die ontdekking deur die hemel, dit wil sê: die hemel ontdek dat die mens die band met God verbreek het. Die titel kan ook wys op die feit dat die hemel deur die mens ontdek word - aanvanklik opgemerk deur Hans Werkman (1992). Albei die temas kom in die boek uitvoerig aan die orde. Die hemel ontdek dat die mens niks meer van die hemel wil weet nie, en dit is 'n hoofkenmerk van die teenswoordige mens. Omgekeerd wil die mens egter vandag juis álles oor die hemel weet, maar dan die hemel in die fisiese sin van die heelal. Een van die boek se hoofpersone is die astronoom Max Delius, wat na die kosmos se diepste geheime op soek is. Dit lyk asof Max op grond van sy navorsing en 'n skielike geniale ingewing ineens die big bang, die heelal se absolute begin gesien het, ja, als ' $t$ ware daarby verby gekyk het tot in ' $n$ ander, tydlose wêreld, wat groter is as die heelal. In werklikheid het Max daarmee, volgens die voorstelling van talle moderne fisici, God self "gesien". In een van sy boeke sê die beroemde fisikus Stephen Hawking (1988) dat, as ons 'n "Teorie van Alles" sal hê, waarin die heelal se diepste kragte met mekaar in samehang gebring is, dat ons dan álles sal verstaan, en daarmee, so eindig sy boek, sal ons die mind of God ken. 'n Ander bekende fisikus, Paul Davies (1983:IX 299; 1984), het gestel: "God is natuurkunde", en: "Myns insiens bied die natuurkunde 'n sekerder weg tot God as die godsdiens". So 'n siening reflekteer wetenskaplikes se hoogmoed teenoor God, want hulle glo dat die fisika vandag die groot grondvrae kan beantwoord wat vroeër deur die godsdiens of deur die filosofie beantwoord is. Die sogenaamde analitiese filosofie het aan die groot metafisiese vrae 'n einde gemaak deur hierdie vrae as "sin-loos" te beskou; die moderne natuurwetenskap daarenteen reken met die grondvrae af deur te beweer dat die fisika hulle beantwoord het

Party bioloë het dieselfde aanmatigende houding. So sê Richard Dawkins aan die begin van sy boek The Blind Walchmaker (1987) dat syns insiens die menslike bestaan, die grootste van alle misterieë, nie langer 'n misterie is nie, deurdat Darwin en Wallace, die grondleggers van die moderne evolusieleer, dit "opgelos" het. Hier sien ons die wetenskap soos 'n toring van Babel, waarvan die spits tot aan die hemel reik. In die roman is dit opmerklik dat Max op die oomblik dat hy hierdie spits bereik, deur 'n meteoriet getref en volkome vernietig word. Op die moment dat hy die heelal se geheim ontdek, word hy 
deur hierdie heelal gedood. Die moderne wetenskap is die mens se grootste uitvinding - maar 'n uitvinding wat ook dreig om hom te vernietig.

Die verband tussen die wetenskap se verhewe, hemelbestormende ontdekkings én die vernietigende krag wat dieselfde wetenskap uitoefen, word in die roman treffend geillustreer deur die reusagtige radioteleskoop in die Nederlandse dorp Westerbork. In die roman het dit besondere betekenis dat in Westerbork enersyds die skouspelagtigste tegnologiese wonder staan wat Nederland ooit voortgebring het, en andersyds dat presies dieselfde plek in Westerbork tydens - die oorlog 'n deurgangskamp vir Jode was, waarvandaan die Jode na die vernietigingskampe in Duitsland vervoer is. 'n Besoek van Max Delius aan Auschwitz, waar sy Joodse moeder vermoor is, speel in die boek 'n belangrike rol. Aan die een kant is Auschwitz tipies vir die postmoderne mens: "die toppunt van die vernietiging van die rede", noem Mulisch dit, "uitbraak van 'n primitiewe en barbaarse opstand teen die Westerse beskawing", sê die roman. Andersyds is die holocaust juis "die toppunt van tegnologiese en burokratiese rede", sê die boek, en in hierdie opsig dus juis 'n tipiese kenmerk van die moderne wetenskap se vernietigende krag (vgl. Van Harskamp, 1995:144). Dalk kan ons vandag dieselfde van Kosovo sê.

Die roman se kern word deur twee soektogte gevorm: die een na die ontstaan van die heelal en die ander een na die Tien Gebooie. Hierdie twee soektogte weerspieël twee fundamentele vraagstukke in die wetenskap (vgl. Aertsen, 1995:86). Die eerste grondvraag hou verband met die soeke na die diepste aard en samehang van die werklikheid. Die tweede grondvraag is die vraag omtrent die menslike etiese handele, die vraag omtrent goed en kwaad. Hierdie twee grondvrae is parallel met mekaar. Die eerste vraag gaan oor die natuurwette waaraan die hele fisiese werklikheid onderworpe is; die tweede vraag handel oor die norme waaraan die menslike handele onderworpe is. As die mens sy moraal versaak het, trek God die grond vir hierdie moraal, die Tien Gebooie, in die hemel terug. So hang die twee soektogte met mekaar saam: die eksplosiewe ontwikkeling van die moderne wetenskap het hand aan hand gegaan met die neergang van die moraal. Volgens die roman is dit veroorsaak deurdat die moderne wetenskap 'n duiwelse verbond met Lucifer, die Satan, gesluit het. As die moderne mensheid egter die hemel prysgee, gee die hemel die Westerse mensheid prys.

In Die ontdekking van die hemel is dit die 17de-eeuse Engelse geleerde Francis Bacon wat as die prototipe van die moderne wetenskaplike beskryf word, dit is die wetenskaplike wat die werklikheid nie net wil ken nie, maar dit soos 'n god wil beheers. Bacon was, sê die boek, "die grondlegger van die wetenskapliktegnologiese moderniteit" (Mulisch, 1992:247). ${ }^{4}$ Juis by Bacon sien ons inder-

$4 \quad \mathrm{Vgl}$. vir sy wysgerige werklikheidsiening ook Mulisch (1980). 
daad hoe die ideale van 'n Christelike wetenskap in 'n spanningsveld tereggekom het. Aan die een kant wil die Christen-wetenskaplike die mensheid dien in die raamwerk van die goddelike kultuuropdrag en die koninkryk van God. Aan die ander kant kan hy hom ook nie onttrek aan die ideaal om die werklikheid te beheers asof die mens self god is nie. Dit is die spanning tussen wetenskap in diens en tot eer van God en wetenskap in diens van die moderne, outonome mens, wat die wetenskap net tot sy eie voordeel gebruik.

In die roman het die terugneem van die Tien Gebooie geweldige gevolge. As dit waar is dat die moderne wetenskap 'n verbond met die duiwel gesluit het, wat sal dan gebeur as die hemel die kontrak met die mensheid, ja, die kontak met die mensheid opgee? Die roman sê: "die hel zal losbreek op aarde" (Mulisch, 1992:899). As die Tien Gebooie teruggeneem word, behou die mens weliswaar steeds die innerlike sedewet, sy morele gewete (Aertsen, 1995:92). Hierdie innerlike sedewet beteken egter niks sonder die verlossing in Christus en die krag van die Heilige Gees, waardeur die mens slegs die goeie kan doen nie. Hierdie evangelie kom in die roman nie voor nie. Dit is egter sekerlik waar dat as God inderdaad sy hand van hierdie wêreld onttrek, die mens met sy hele mooi ingeskape sedewet eenvoudig verlore is Die roman betoog dat "rebellerende" wetenskap, soos dit in die Renaissance begin het en deur die Verligting versterk is, eindig by Hiroshima en Auschwitz. Die roman praat in verband met die wetenskap wat 'n Hiroshima en 'n Auschwitz voortgebring het, van "die reusagtige triomf van wetenskap en tegniek in die twintigste eeu" (Mulisch, 1992:247), maar dit gaan om wetenskap en tegniek wat vir massavernietiging van die mens misbruik is.

'n Christelike universiteit is 'n plek waar 'n mens 'n fundamenteel ander tipe wetenskapsbeoefening mag verwag. Graag wens ek die Potchefstroomse Universiteit daarom baie seen en wysheid toe vir die tyd wat voorlê. Mag dit 'n universiteit wees wat 'n verskil maak. Dan sal daar egter baie nagedink moet word oor die relevansie van die Christelike geloof - nie net vir die wetenskap nie, maar ook vir die gewone praktyk van die Christelike lewe. Dan sal ons moet leer om te breek met die mentaliteit van die moderne en postmoderne Westerse mens. Dit is vreeslik moeilik, want ons het hierdie mentaliteit almal met moedersmelk ingekry; daarom het ons baie genade nodig. Dit is hierdie genade van die Here wat ek die PUK toewens.

\section{Bibliografie}

AERTSEN, J.A 1995 Metafysica in De ontdekking van de hemel. (In Haan, W. et al., Mulisch en de wetenschap Kampen : Kok p 86-95.)

DAVIES, P 1983 God and the New Physics Harmondsworth: Penguin Books.

DAVIES, P 1984 Superforce New York : Simon \& Schuster.

DAWKINS, R 1987. The blind watchmaker. Harlow : Longman

DE ROVER, Fr 1995 Harry Mulisch ontdekt. Amsterdam : Bert Bakker

ECO, U. 1983. De naam van de roos. Amsterdam Bert Bakker. 
ECO, U 1989 De slinger van Foucault. Amsterdam : Bert Bakker.

ECO, U. 1995. Het eiland van de vorige dag. Amsterdam : Bert Bakker.

HAAN, W., VAN HARSKAMP, A, JANSEN, Y \& SIERTSEMA, B red 1995. Mulisch en de wetenschap. Kampen : Kok.

HAWKING, S. 1988 A brief history of time. Toronto : Bantam Books.

MULISCH, H. 1980. De compositie van de wereld Amsterdam : De Bezige Bij

MULISCH, H. 1992. De ontdekking van de hemel. Amsterdam : De Bezige Bij

OUWENEEL, W.J. 1997. Wijs met de wetenschap: Inleiding tot een christelijke wetenschapsleer. Leiden : Barnabas.

STEENHUIS, P H 1995. Alles is altijd uit de bijbel. Amsterdam : De Bezige Bij.

VAN HARSKAMP, A 1995. Het symbool 'Auschwitz' in De onidekking van de hemel. (In Haan, W. et al. Mulisch en de wetenschap. Kampen Kok p. 120-145.

WERKMAN, H. 1992. Harry Mulisch en de gewiste software van Moses. Nederlands Dagblad, Des. 19 